\title{
Çocukluk çağı kalça hastalıklarında femoro-asetabular sıkışma sendromu
}

\section{Femoro-acetabular impingement syndrome in childhood hip diseases}

\author{
Altuğ Yücekul, Cemalettin Aksoy \\ Hacettepe Üniversitesi Tıp Fakültesi, Ortopedi ve Travmatoloji Anabilim Dalı, Ankara
}

\begin{abstract}
Femoro-asetabular sıkışma sendromu günümüzde erişkin yaş grubunda erken osteoartrite yol açan önemli bir sorun olarak karşımızda bulunmaktadır. Çocukluk yaş grubunun sık görülen bazı kalça hastalıkları da bu duruma yol açabilmektedir. Legg-Calvé-Perthes hastalığı da femur başını deforme ederek femorasetabular sıkışmaya yol açabilir. Günümüzde kullanılan emniyetli kalça dislokasyonu bu sorunun çözümü için bir yöntem olabilir. Ancak, tedaviye karar vermeden önce, geç dönem sonuçlarının mutlaka görülmesi gerekir.
\end{abstract}

Anahtar sözcükler: Perthes hastalı̆̆ı; cerrahi kalça dislokasyonu; femoro-asetabular sıkışma
Femoro-acetabular impingement is a serious and commonly seen disorder causing early osteoarthritis in adult population. But this disease can be diagnosed in pediatric age group mainly secondary to the commonly seen pediatric hip diseases. Legg-Calvé-Perthes disease also may cause femoro-acetabular impingement by deforming the femour head. Surgical hip dislocation can be a good approach to the treatment of this problem. However, late results must be evaluated before a final decision.

Key words: Legg-Calvé-Perthes disease; surgical hip dislocation; femoro-acetabular impingement
emoro-asetabular sıkışma, ağrılı kalçalarda asetabular kenar ile femoral baş-boyun bileşkesinin patolojik ilişkisinden kaynaklanmaktadır. Geçmiş yıllarda özellikle erişkin kalçada femoro-asetabular sıkışma ve tedavi yöntemlerine yoğun ilgi duyulmuş, bu konuda araştırmaların ve yayınların sıklığı artmıştır. Bilinmektedir ki altta yatan etiyolojik faktörler, femur baş ve boynu ile asetabulum arasındaki ilişkiyi bozan morfolojik değişikliklerdir. Bu morfolojik değişiklikler süreç içerisinde asetabular labrum yaralanmaları, kıkırdak hasarı ve osteoartritik eklem dejenerasyonuna yol açar. Ancak, pediatrik yaş grubunda artan femoro-asetabular sıkışma tanısına ve tedavisine rağmen, mevcut araştırmalar ve yayınlar oldukça yetersizdir. Bu nedenle, hastalığın semptomlarını bilmek, deformitenin gelişimine neden olan faktörleri belirlemek ve semptomatik kalçada tedavi çeşitlerini geliştirmek açısında önemlidir.

Femoro-asetabular sıkışma iki alt başlıkta incelenir. Bunlarda birincisi, anormal femoral baş-boyun bileşkesinin büyümesiyle görülen cam tipi lezyonlar (anormal anterior femoral boyun) ve ikincisi, anterior asetabular kenarın femur başını aşırı örtmesiyle görülen pincer tipi (kıskaç sıkışma) lezyonlardır. Cam tipi lezyonlarda sıkışmanın nedeni, proksimal femurun asetabulumun hacminden büyük kenarlı olmasıdır. Sonuçta, asetabular kıkırdakta ve asetabulum superior anterior duvarındaki labrumda abrazyona, kıkırdak delaminasyonuna neden olur. ${ }^{[1,2]}$ Daha çok pediatrik yaş grubunda görülen ve etiyolojisinde pediatrik yaş grubu hastalıkları görülen tiptir. Özellikle, Legg-Calvé-Perthes hastalığı, orta derece avasküler nekroz, femur başı epifiz kayması (FBEK) ${ }^{[3]}$, atravmatik gelişim ${ }^{[4]}$, kötü kaynamış femur boyun kırıkları ve geçirilmiş femoral osteotomiler, cam tipi lezyonların etiyolojisinde yer alır. Pincer tipi sıkışmada ise neden, anormal yapıdaki asetabulumdur. Derin veya retrovert asetabulumun aşırı örtünmesi sonucunda labrum ezilir; tekrarlayan posterior femoral subluksasyon neticesinde ise karşıt mekanizmalarla (contrecoup) asetabulum infero-mediyal eklem kıkırdağında hasara neden olur. Daha çok orta yaş bayan

- Illetişim adresi: Prof. Dr. Cemalettin Aksoy, Hacettepe Üniversitesi Tıp Fakültesi, Ortopedi ve Travmatoloji Anabilim Dalı, Ankara Tel: 0312 - 4667410 e-posta: aksoyc@hotmail.com

- Geliş tarihi: 20 Șubat 2017 Kabul tarihi: 20 Șubat 2017 
rahatsızlığı olarak görülür ve etiyolojisinde asetabular retroversiyon, koksa profunda, protrusio asetabuli ${ }^{[5]}$ yer alır. Aynı zamanda, pediatrik yaş grubunda gelişimsel kalça displazisi için yapılan pelvik osteotomiler (özellikle triple pelvik osteotomi, periasetabular osteotomi) femoro-asetabular sıkışmaya yol açabilir. Ancak, erişkinden farklı olarak, çocuklarda var olan yeniden şekillenme potansiyeli, bu aşırı düzeltmelerin ne kadarının klinik önemi olan sıkışmaya yol açtığını bilinmez hale getirmektedir. Femoro-asetabular sıkışma, çocukluk çağında ilk kez gelişimsel kalça displazisi hastalarında uygulanan periasetabular osteotomilerin bir sonucu olarak fark edilmiştir. ${ }^{[6]}$ Çocukluk çağı femoro-asetabular sıkışma ile konjenital kalça hastalıklarının (femur başı epifiz kayması ve LeggCalvé-Perthes) $)^{[7,8]}$ ilişkisini gösteren çok sayıda yayın bulunmaktadır. Mevcut tanı almış rahatsızlığı bu hastalıklar olmayan kişilerdeki femoro-asetabular sıkışmaya ise, femur başı epifizindeki düzensiz büyümeye ikincil anormal gelişim süreci neden olabilmektedir. ${ }^{[9]}$

\section{Klinik ve Tanı}

Kalça sıkışması, genellikle aktif genç hastalarda oldukça ani başlangıçlı kalça ağrısı ile kendini gösterir. Özellikle sıkışma sendromu tanımlandığından beri bilinen kalça rahatsızlığı olmayan hastalar da buna dahil olmak üzere, adolesanlarda daha sık olarak görülmektedir. Sıklıkla, ortada ilk semptomun başlamasına neden olan minör travma öyküsü vardır. Ağrı, aralıklı başlayabileceği gibi, kademeli olarak artarak devamlı bir hal alabilir. Kalça eklemini fleksiyona getiren aktiviteler ağrıyı şiddetlendirirken, tipik olarak öyküde ağrının oturma veya öne eğilme ile arttığı görülür. Ağrının lokalizasyonu, uyluk anterioruna ve lateraline yayılım gösteren anatomik femur başı hizasında ( $C$ belirtisi), özellikle eşlik eden labral lezyon varlığında, yakalama veya patlama tipinde keskin tarzdadır.

Muayenede, kalçanın tipik olarak iç rotasyon, adduksiyon ve fleksiyonda kısıtlı hareketi mevcuttur; sıkışma testleri tanı koymada yardımcı olur. Anterior sıkışma testinde, yatar pozisyonda bulunan hastada kalça iç rotasyonda ve adduksiyonda iken nazikçe kalçanın fleksiyonu ve ekstansiyonu yapılır. Kondral veya labral lezyondaki makaslama kuvvetine bağlı keskin bir ağrı hissedilir. Bu testin modifikasyonu olan bisiklet testinde ise, hasta etkilenen kalçası havada olacak şekilde lateral yatarken, kalça addukte pozisyondayken fleksiyon ve ekstansiyon döngüsünde ağrısının varlığı, labral patolojiyi ve sıkışmayı gösterir.

Kalça displazisi olan hastalarda, özellikle internal ve eksternal rotasyonda, eklem hareket açıklığı tama yakın olarak görülür. Femur başının kapsamasının yetersiz olması hareket kısıtlılığının daha az olmasına neden olmakta iken, pincer tipi aşırı kapsama durumunda hareket kısıtlılığı çok fazla olmaktadır.

FABER mesafe testinde ise, dizin lateralinin muayene masasına olan mesafesine bakılır. Kalça fleksiyon, abduksiyon ve diş rotasyondayken, lateral kondilin muayene masasına mesafesi ölçülür ve sağlam taraftaki mesafe ile karşılaştırılır. Semptomatik kalçada daha fazla mesafe olması, testin pozitif olduğunu gösterir. Bu noktada, femoro-asetabular sıkışmada FABER'de hareket kısıtlılığının neden gerçekleştiği biyomekanik olarak tam bilinmese de, yapılan çalışmalarda hasta korkusunun birincil neden olduğu düşünülmektedir. İlgi çekici olan; cerrahi olarak doğrudan mekanik sıkışma görülmediği halde, artroskopi sonrasında FABER mesafelerinde iyileşme görülmesidir. ${ }^{[10]}$

Son olarak, arada kalınan durumlarda, ağrının intra-artiküler patoloji zemininde gelişip gelişmediğini değerlendirmek için intra-artiküler lokal anestezik enjeksiyonu yardımcı olabilmektedir.

Genel anlamda, sıkışma muayenesi erişkinden önemli farlılıklar göstermez.

\section{Görüntüleme}

En önemli iki görüntüleme yöntemi; anteroposterior pelvis grafisi ve proksimal femur aksiyel yan grafisidir. Anteroposterior pelvis grafisi ile, asetabular örtünme, eklem mesafesi ve fiziyel durum değerlendirilebilir. Asetabular displazinin derecesi, sourcil, asetabular indeks ve lateral merkez köşe açısına bakılarak değerlendirilebilir. Pincer tipi sıkışmada ise, retrovert yerleşimli bir asetabulumda, asetabulum arka duvarı ön duvara göre mediyal yerleşim gösterir (cross-over bulgusu), protrusio asetabuli gibi asetabulum derinliğinin arttığı durumlarda, femur başı asetabulum tarafından tamamen örtülür.

Cam tipi sıkışmada ise, femur baş-boyun bileşkesinin ön-yandaki düzleşmeye bağlı olarak epifizyel skar arkı, yana doğru yayılım gösterir ve bu pistol grip deformitesi olarak adlandırılır. ${ }^{[11]}$ Pistol grip deformitesin femoro-asetabular sıkışmada prognostik olduğu düşünülmektedir. Cross-table lateral grafide, supin pozisyondaki hastada kalça $15^{\circ}$ iç rotasyonda ve kontrolateral kalça tam fleksiyondayken ölçülen alfa açısı değerlendirilir. ${ }^{[3]}$ Manyetik rezonans (MR) görüntüleme ile, labral yırtıklar, kondral lezyonlar ve çevre yumuşak dokular değerlendirilebilmektedir. Femoral anteversiyonda geniş labral yırtıklar ve iç ve dış rotasyonda kısıtlılık mevcuttur. ${ }^{[12]} \mathrm{MR}$ görüntüleme ve $X$-ray ile fizisler değerlendirilir ve eğer fizisler açık ve cam fizise yakın ise, açık fizislere zarar vermemek için 
tedavi ertelenebilir. Ancak, tedavi gerektiren hastaların önemli bir bölümü adolesan yaş grubunda olduğu için, bu durum (fizisin halen tam kapalı olmaması) ciddi bir engel oluşturmamaktadır.

Radyolojik görüntüleme kriterleri de erişkinden önemli farklılıklar göstermez.

\section{Tedavi}

\section{Cerrahi harici yöntemler}

Femoro-asetabular sıkışma tanısı almış her hastada, başlangıç tedavisi öncelikle konservatiftir. Geç dönem sonuçları tam olarak bilinmediği ve halen hasta seçimi konusunda tereddütlerin mevcut olduğu gerçeği hatırlanarak, gereksiz cerrahi girişimlerden kaçınmak çok önemlidir. Başlangıç tedavisi olarak NSAii, fiziksel terapi ve aktivite modifikasyonu önerilmektedir. Hastaların yakınmaları bu dönem içinde izlenmelidir. Ancak, çoğu durumda medikal müdahale yeterli değildir. Kalçada gerçekten sıkışma durumu mevcutsa, semptomlar devam etmektedir ve hastalar alternatif tedavi yöntemlerini sorgulamaktadır. Çocukluk yaş grubunda, genç erişkinlerden farklı olarak, cerrahi talebi daha az olmaktadır. Bu aşamada ayırıcı tanı çok dikkatli biçimde yapılmalı, benzer klinik duruma yol açabilecek çocukluk çağı hastalıkları araştııılmalıdır. Fakat, yakınmaların femoro-asetabular sıkışmaya bağIı olduğu net biçimde ortaya konulmuş ise, bu noktada gelişimsel kalça displazisindeki gibi herkes tarafından kabul gören ve uygulanan, kalçayı korumak için erken cerrahi düşünülmelidir.

\section{Cerrahi yöntemler}

Ganz ve arkadaşlarının tanımladığı trokanterik osteotomiyle beraber, cerrahi kalça dislokasyonu ile femur boynu, tekrar şekil verilmesi için oldukça iyi görülebilmektedir. Cerrahi dislokasyon ile, özellikle anterolateral kambur kolayca temizlenebilmekte, femoral baş-boyun ofseti bu bölgedeki kemiğin temizlenmesi ile tekrar oluşturulmaktadır. Ancak, erişkinde kısa dönem sonuçları iyi olsa da, açık fizisli çocuk hastalar sadece avasküler nekroz değil, akut femur başı epifiz kayması gelişmesi bakımından da risk taşımaktadır. Femur boynunun temizlenmesinde, özellikle kırık gelişmesi veya femur başı avasküler nekrozundan kaçınma oldukça önemlidir. Literatürde, femur boynu rezeksiyonu \%30'un altında tutulduğunda kırık riskinin daha az olduğu gösterilmiştir. ${ }^{[13]}$ Yine, temizlenecek lezyon anterolateral yerleşimli ise, posterior ve posterosuperior assendan damarların korunması oldukça önemlidir. Bu nedenle, tanımlanmış cerrahi tekniğe mutlak uyum, avasküler nekroz komplikasyonlarından kaçınmak için şarttır.
İzole pincer tipi sıkışmalar çocukluk çağı kalça hastalıklarında nadir olarak görülür ve adolesan çağdaki tedavi yöntemleri konusunda yeterli bilgi bulunmamaktadır. En sık neden, yapılmış olan triple veya periasetabular osteotomiler ile aşırı düzeltme elde edilmiş olmasıdır.

Asetabular retroversiyon varlığında, reverse periasetabular osteotomiler ( $Y$ kıkırdağının kapalı olduğu olgularda) veya modifiye triple osteotomi uygulanabilir. Cerrahi dislokasyon ile, asetabular tarafta labrum tamiri ve anterolateral asetabular köşe tamiri uygulanabilir. Ancak, erişkinde ne kadar güvenli görülse de, çocukluk çağında asetabular büyüme merkezlerine cerrahi esnasında dikkat edilmelidir. Geçmişte femoroasetabular sıkışma hastalarında tedavi seçenekleri açık cerrahi dislokasyon ve osteoplasti ile sınırlıyken, günümüzde kalça artroskopisiyle beraber, pediatrik popülasyonda da erişkindekilere benzer iyi sonuçlar elde edilebilmektedir. ${ }^{[14]}$ Ancak, pediatrik kalça artroskopisi erişkinlerdeki gibi standart bir metod değildir. Ayrıca, kompleks sorunu olan hastalarda -ki çocukluk yaş grubundaki hastaların önemli bir bölümünde ek sorunlar mevcuttur (trokanterik aşırı büyüme, femur başında şekil bozuklukları, tüm başı içeren hump lezyonları)kalça artroskopisi tekniği bu sorunların tümünü ortadan kaldırmaktan halen uzaktır. Bu nedenle, kompleks sorunu olan hastalarda halen öncelikli olarak açık metodlar tercih edilmelidir. Özellikle pediatrik hastalarda, kompleks intra- ve ekstra-artiküler sorunların çözümü gerektiği için, açık metodlar gerçek anlamda tüm patolojik durumlara yanıt verebilmektedir.

Pincer tipi lezyonların tedavisinde asetabular lezyonun aşırı miktarda düzeltilmesi, iyatrojenik asetabular displaziye yol açabilmektedir. Bu nedenle, kontrolsüz düzeltmelerden kaçınmak gerekir. Labral yırtıkların varlığında, debridman ve sütüre ankor ile onarım yapılmaktadır. Kondral lezyonlarda, kondroplasti ve mikro-kırık yapılarak lezyon stabilize edilmeye çalışılır. Osteokondral lezyonların varlığında, lezyonun debrimanı, greftlenmesi ve başsız vidalarla tespiti, adolesan hastalarda uygulanabilir.

Protrusio asetabuli mevcut ise proksimal femoral valgus osteotomisi uygulanabilir ve tedaviyi tamamlayıcı olarak, triradiat kıkırdağın epifizyodezi yararlı olabilir.

Cam tipi lezyonu olan hastalarda ise, lezyon açık fizisler ile ilişkili değilse dekompresyon amaçı kısıtlı osteoplasti yapılabilir; ancak, lezyon fizis ile ilişkili ise, osteoplasti fizis kapandıktan sonra ikinci bir seansa bırakılabilir veya semptomatik hastalarda açık fizise rağmen osteoplasti yapılabilir.

Açık ve artroskopik cerrahide dikkat edilmesi gereken en önemli husus, sadece labrum tamiri ve hump 
rezeksiyonu tedavi için yeterli değildir. Pediatrik yaş grubunda sıklıkla görülen eşlik eden patolojik durumlara müdahale edilmezse, hastanın yakınmaları devam edecektir.

Hastalarda tedavi kararı verilmeden önce; ekstremite uzunluk farklılıkları ve eşlik eden dismorfik sendromların araştırılması, kemik displazileri yönünden hastaların değerlendirilmesi, alt ekstremite profilinin mekanik bozukluklar yönünden değerlendirilmesi, mukopolisakkaridoz gibi eklem morfolojisini bozan hastalıkların araştırılması, tedavinin başarısı açısından çok önemlidir. Aksi takdirde hastanın yakınmaları devam edecektir.

\section{Femur Başı Epifiz Kaymasında Sıkışma Sendromu}

Femur başı epifiz kayması, ergenlik döneminde sık görülen kalça sorunlarından biridir. Femur üst ucundaki büyüme plağının zayıflaması ve aşııı vücut ağırlığının etkisiyle, makaslama kuvvetlerine bağlı olarak, femur üst uç epifizi asetabulumda kalırken, femur boynunun öne doğru yer değiştirmesi sonucu görülür. Standart tedavisi in-situ fiksasyondur. Bu durum, iki mekanizma ile sıkışmaya neden olabilir. Kaymış epifizi in-situ tespit etmek için, fizise dik femur başının merkezine bir vida gönderilir. Vida, femur boynunun anteriorunda ise asetabular köşeye dayanabilir. ${ }^{[15]}$ íkinci ise; femur başı posteriora kayarsa anterolateral metafiz açığa çıkar ve in-situ tespit edilirse büyük bir anterolateral yumru oluşur ve asetabulum köşesine sıkışır. Ancak, uzun dönem sonuçlarda femur başı epifiz kaymasında in-situ pin'leme en çok tercih edilen tedavi yöntemidir ve çoğu hastada yumru kendiliğinden remodelize olmaktadır. ${ }^{[16]} \mathrm{Ne}$ yazık ki, bu sıkışan yumru, remodelize olmadan çok önce asetabulumdaki labrum ve kıkırdağa zarar vermektedir. ${ }^{[17]}$ Burada bilinmesi gereken, femoro-asetabular sıkışmanın ortaya çıkaracağı klinik tablo ile kayma derecesi arasında belirgin bir ilişki olmadığıdır. Metafizyel yumruyu temizlemek ve femur boynuna tekrar şekil vermek, proksimal femur deformitesi ileri derecede değilse, labrumu korumaya yeter. Ancak, hafif tip femur başı epifiz kayması haricinde, sadece boyuna tekrar şekil vermek gibi basit tedavi seçenekleri yeterli değildir. Bu durumlarda, proksimal femoral osteotomiler ile beraber femur boynunun dekompresyonu gerekmektedir. İkisinin de aynı anda ya da iki farklı seans halinde yapılıp yapılmayacağı konusu ise net değildir.

Southwick ${ }^{[18]}$ Imhauser ${ }^{[19]}$ Dunn ${ }^{[20]}$ proksimal femur osteotomileri ile femur başı sıkışmadan uzaklaştırmaya çalışılmaktadır. Osteotomilerin neticesinde, yük taşıyan kısım merkezi intra-artiküler kıkırdak olmakta ve yumru veya osseöz anomali asetabular köşeden temizlenmektedir.
Günümüzde, femur üst uç epifiz kayması şiddetli ise in-situ pin'leme artık ideal bir tercih değildir. Bu tercih, cerrahi dislokasyonla açık redüksiyon yapılması ve izlemde sıkışma sendromlarının ortaya çıkmasını engellemek açısından önemlidir. ${ }^{[21]}$

In-situ pin'lenmiş ve sıkışma sendromu, hareket kısıtlılığı olan hastalarda da, hem femur başındaki deformitenin giderilmesi ve eşzamanlı hareket açıklığının sağlanması için cerrahi dislokasyonla femur başının şekillendirilmesi hem de mevcut ise labrum lezyonlarının tamiri mümkündür. Bu hastalarda deformite kompleks olduğu için, özellikle şiddetli deformitenin varlığında, açık metod halen daha etkin görülmektedir.

Proksimal femoral osteotomiler, avasküler nekroz açısından, femur boyun ve subkapital osteotomilerden daha güvenlidir; ancak, deformiteye uzaklık arttıkça, osteotomi sonrasında zig-zag tipinde deformite oluşmakta ve siyatik sinir irritasyonuna neden olmakta ve gelecekte ihtiyaç duyulabilecek total kalça artroplastisi cerrahisini zorlaştırmaktadır. Bu nedenle günümüzde tercih edilmemektedir.

\section{Legg-Calvé-Perthes Hastalığında Sıkışma Sendromu}

Legg-Calvé-Perthes hastalığı, femur başı epifizinin avasküler nekrozu sonrasında ölü kemiğin ortadan kaldırılması ve yeni kemik oluşumuyla seyreden bir hastalıktır. Yeni kemik oluşumu sonrası yeniden şekillenme süreci ise, iskelet gelişimi tamamlanana dek sürer.

Perthes hastalığında, parsiyel ekstrude olmuş ve genişlemiş femur başı, kalçanın fleksiyonu ve iç rotasyonuyla beraber, anterior asetabular köşeye sıkışmakta ve ağrı ile artiküler yüzde hasara neden olmaktadır (Şekil 1). ${ }^{[22]}$

Geçmiş uygulamalarda, femur başındaki sıkışmayı iyileştirme amacıyla yapılan çeliektomiyi takiben erken sonuçlara bakıldığında, ciddi problemlerle karşılaşıldığı görülmektedir.

Günümüzde, Legg-Calvé-Perthes hastalarında hastalığa sekonder olarak oluşan, femur başında büyüme, femur boynunda kalınlaşma ve kısalma, rölatif trokanterik aşırı büyüme ve rölatif asetabular displazi, daha etkin biçimde tedavi edilmektedir.

Femur başındaki büyümeler, hump rezeksiyonu veya baş küçültme (nekrotik orta segmentin çıkarılması), aşırı trokanterik büyüme, cerrahi dislokasyon yapılarak rölatif femoral boyun uzatma ve trokanter transferi ve rölatif asetabular displazi, periasetabular osteotomilerle düzeltilebilmektedir. Ancak, bu işlemlerde standart cerrahi dislokasyon teknikleri modifiye edilmekte ve trokantere damar hasarının engellenmesi için posteriordan ek kesi yapılmaktadır (Şekil 2). ${ }^{[23]}$ 


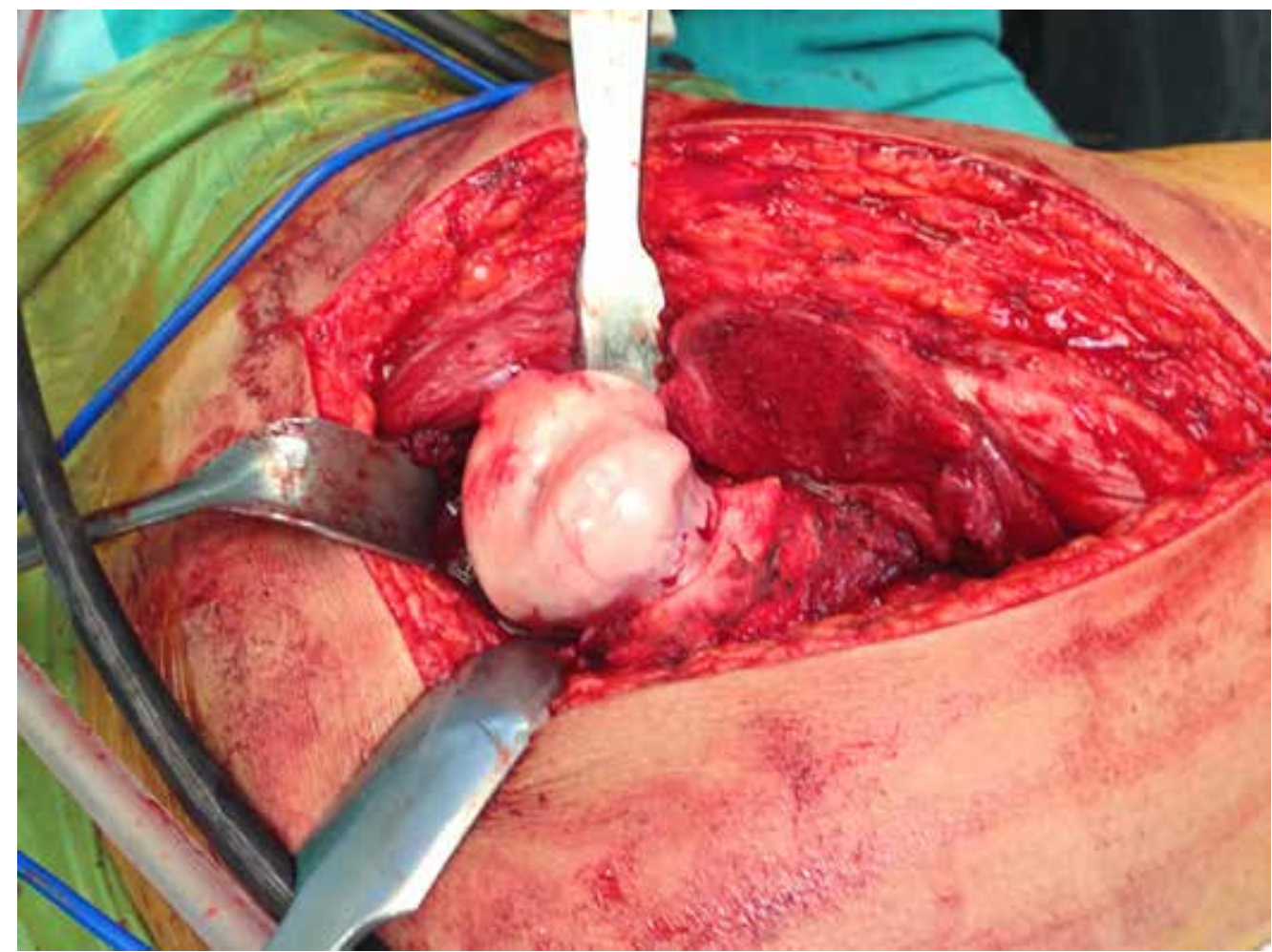

Şekil 1. Legg-Calvé-Perthes hastalığında femur başında bulunan ve sıkışmaya yol açan hump görüntüsü.

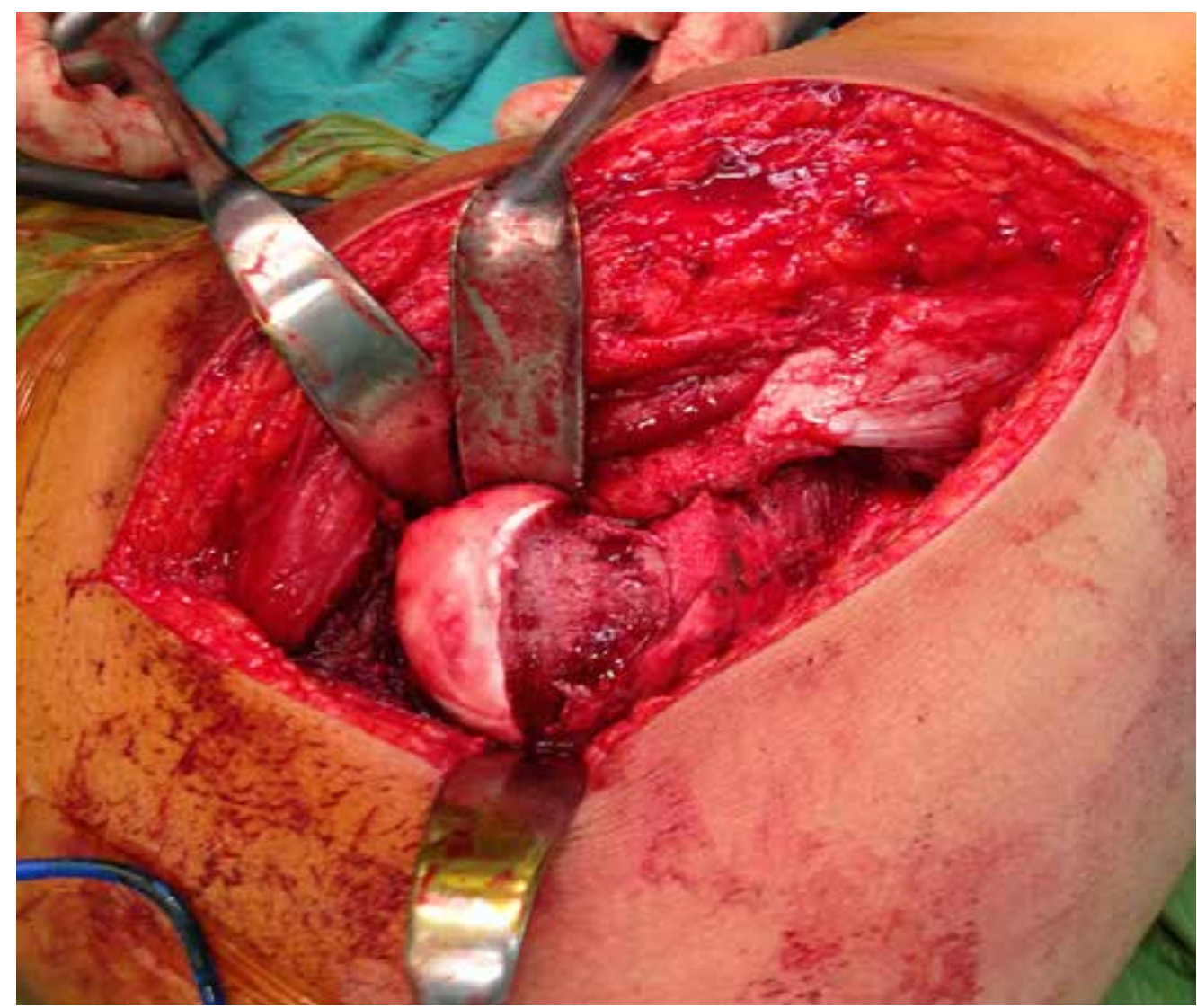

Şekil 2. Şekil 1'de görülen hastanın hump rezeksiyonu sonrasında elde olunan baş görüntüsü. 

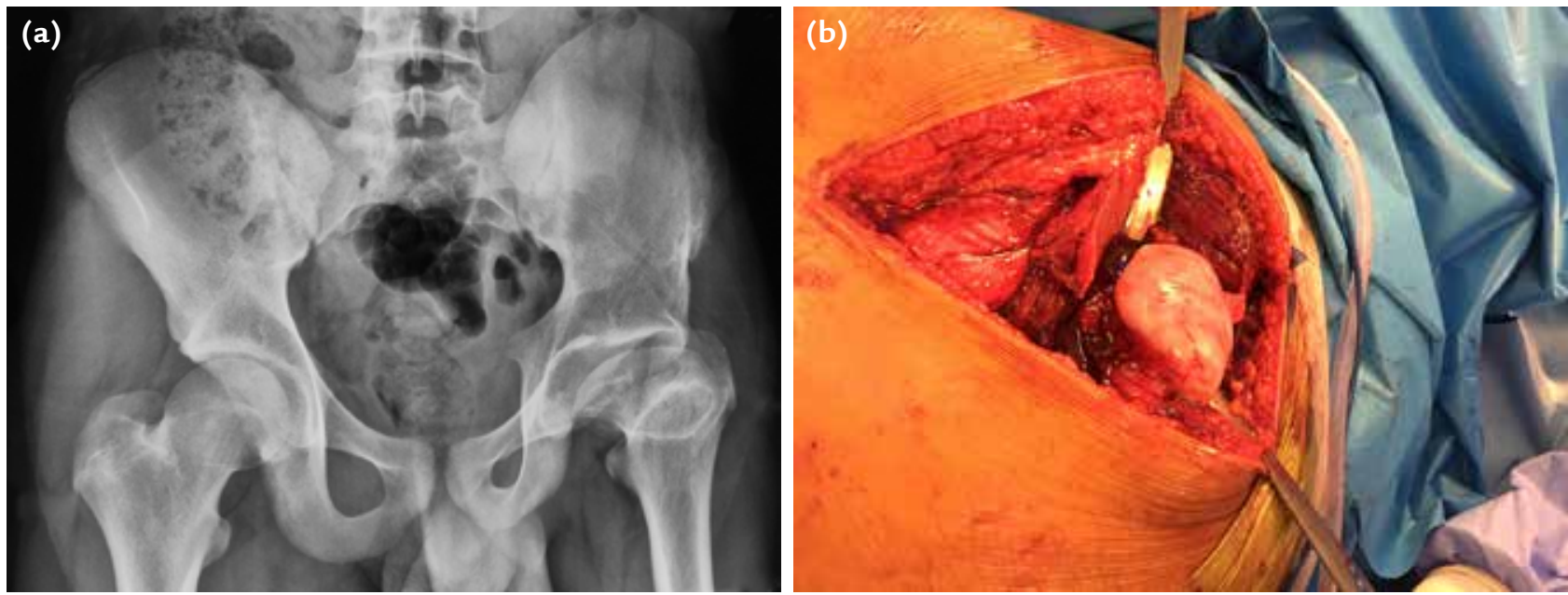

Şekil 3. a, b. Legg-Calvé-Perthes hastalığı sonrasında femur başında hump görüntüsü ve deformasyonun radyolojik görüntüsü (a). Cerrahi dislokasyon sonrasında femur başının görüntüsü (b).
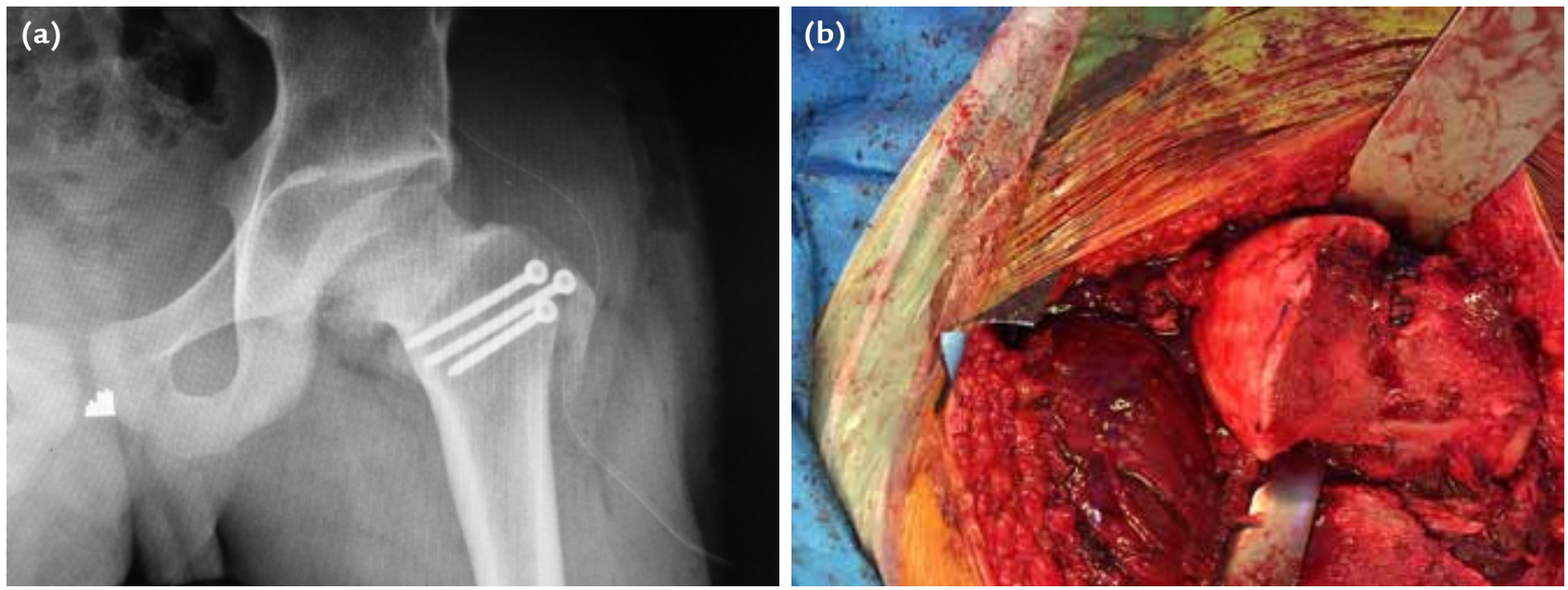

Şekil 4. a, b. Hump rezeksiyonu ve rölatif femur boyun uzatma işlemi sonrasında radyolojik görüntü (a). Cerrahi dislokasyon esnasında femur başından hump rezeksiyonu ve boyun uzatma işleminin görüntüsü (b).

Rölatif femur boyun uzatma işlemleri cerrahi dislokasyon teknikleri ile gerçekleştirilmekte ve bu şekilde hastalarda fonksiyonel kazanımlar elde edilmektedir (Şekil 3 ve 4).

Catterall ile popülarize olan valgus osteotomileri, geç dönem sıkışma sendromunu engelleme konusunda alternatif bir yöntem olarak kullanılabilir; izole baş deformitelerinde uygun bir yöntem olarak önerilebilir. ${ }^{[24,25]}$

\section{Gelişimsel Kalça Displazisi Tedavisi Sonrasında Ortaya Çıkan Femoro-asetabular Sıkışma Sendromu}

Gelişimsel kalça displazisi tedavisi sonrasında, temel olarak iki nedenden dolayı sıkışma sendromları ortaya çıkmaktadır. Bunlardan ilki, femur başı avasküler nekrozu sonrasında ortaya çıkan morfolojik değişiklilere bağlı olanlar ve ikincisi, tedavi amacı ile yapılan pelvik osteotomilerde aşırı örtünmeye ikincil olarak ortaya çıkan sıkışma sendromlarıdır.

Avasküler nekroz sonrasında, femur başında şekil bozuklukları ve trokanterik aşırı büyüme sonucunda sıkışma meydana gelebilir. Bu durumlarda, sıkışma morfolojik olarak başı ilgilendirmeyen ancak boyun-cisim açısında değişikliklerden kaynaklanıyorsa, femoral osteotomiler tedavi için yeterlidir; ancak, femur başında deformasyona yol açıyor ise femur başının inta-artiküler cerrahi ile şekillendirilmesi gerekli olabilmektedir. 


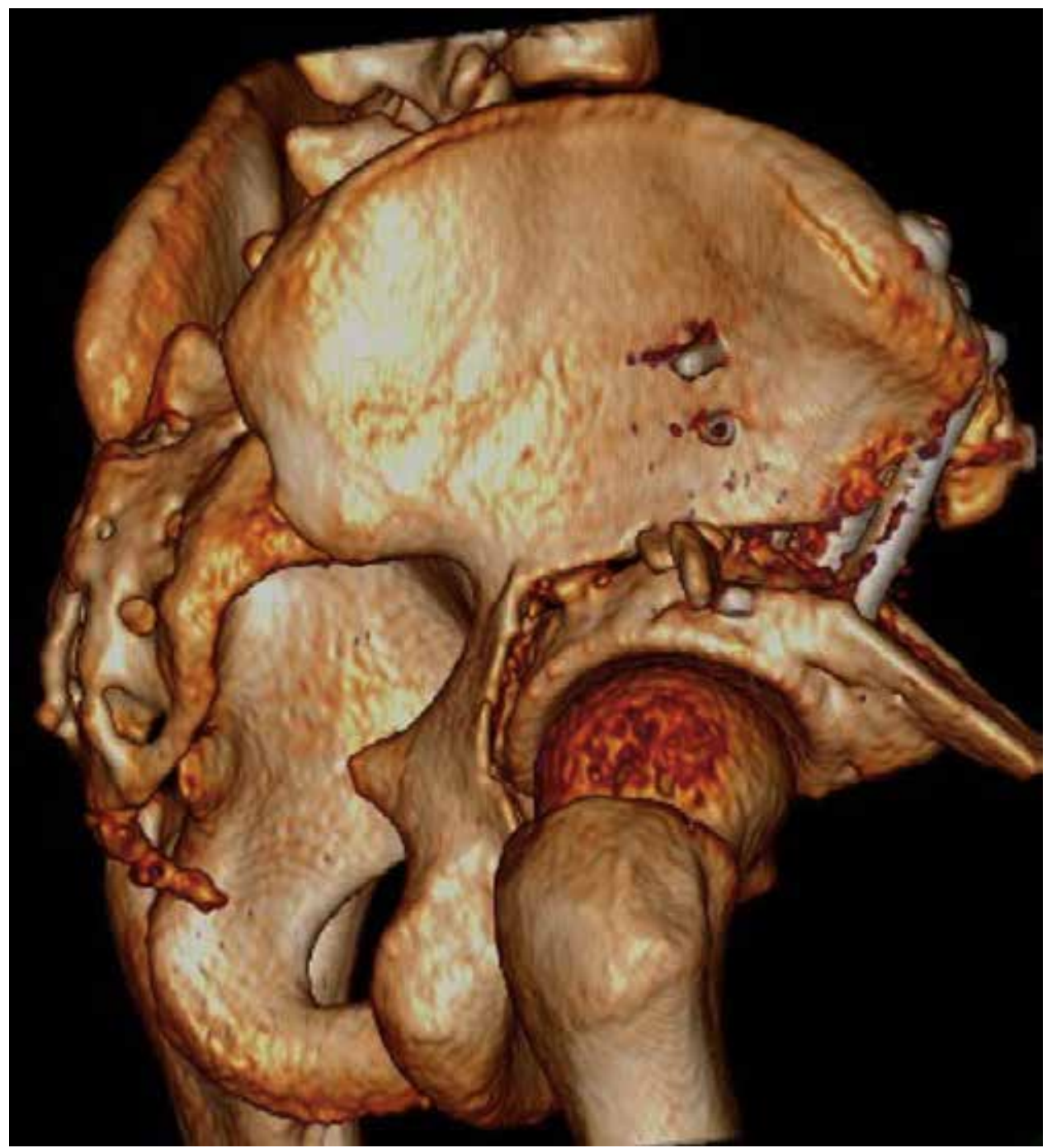

Şekil 5. Ganz periasetabular osteotomi sonrasında meydana gelen aşırı düzeltme ve bunun yol açacağı pincer tipi sıkışmanın 3D tomografik görüntüsü.

Tedaviye ikincil asetabular aşırı örtünmeler, yazarın deneyimine göre, özellikle küçük yaşlarda yapılan pelvik osteotomilere bağlı ise, büyük oranda yeniden şekillenme ile düzelmekte ve önemli bir klinik soruna yol açmamaktadır. Ancak, adolesan veya geç adolesan dönemde yapılan aşırı örtünmeler, genellikle yeniden şekillenmemekte ve hastaların bazılarında klinik semptom yaratmakta ve tedaviyi gerekli kılmaktadır (Şekil 5).

Gelişimsel kalça displazisi tedavisi bu yönüyle de önemlidir. Bu nedenle, tedavi edilen hastalar sıkışma sendromu için de takip edilmeli ve sorunları var ise giderilmelidir. Ana kural burada da geçerlidir. Gelişimsel kalça displazili hastalar, büyüme döneminin sonuna kadar izlenmelidir.

\section{Çocukluk Çağı Sıkışma Sendromu Görülen Diğer Kalça Hastalıkları}

Çocukluk çağının birçok diğer hastalığında sıkışma sendromları ortaya çıkabilir. Hastalarda klinik anlamI yakınmalar mevcut ise, yapılacak tedaviden hastalar yarar görebilmektedir. Ancak, kemik displazileri, dismorfik diğer sendromlar, artrogripotik sendromlar gibi durumlarda, hekimin standart yaklaşım içinde bulunmaması gerekir. Hastalı̆̆ın doğal seyrinin belirlenmesi, yumuşak doku sorunlarının ortaya konulması, eşlik eden sistemik hastalıkların değerlendirilmesi, başarı için önemlidir. Aksi takdirde, bu cerrahi girişimlerin morbiditesi artmakta ve hastalara ilave sorunlar çıkarılmaktadır. Özellikle sendromik durumlarda, sıkışma 
sendromu tedavisi yapacak hekimlerin kalça cerrahisi hakkında ileri derecede deneyimli olması, başarıyı belirleyen faktörlerden biri olmaktadır.

\section{SONUÇ}

Femoro-asetabular sıkışma sendromunun, labrum yırtığı oluşturduğu ve bu klinik olarak belirgin bir sorun haline geldiğinde, dejeneratif artrit sürecini tetiklediği genel kabul görmektedir. Sıkışma sendromlarının çoğu, çocukluk çağı hastalıkları olan gelişimsel kalça displazisi, Perthes, femur başı üst uç epifiz kayması ve femoral baş-boyun ofsetinin eksik olduğu anatomik rahatsızlıklarda görülmektedir.

Femoro-asetabular sıkışma sendromu tedavisi, özellikle erişkin ortopedisinde normal kalça biyomekaniğinin elde edilmeye çalışılması nedeniyle ön plandadır. $\mathrm{Bu}$ durum, çocukluk çağında da sıkışmaya yol açan hastalıklar için geçerlidir. Bu nedenle, çocukluk çağında femoro-asetabular sıkışma sendromuna yol açabilecek hastalıkların doğal seyri bilinmeli, bu hastalar takip edilmeli ve gerektiğinde tedavi edilmelidir.

Gereksiz girişimlerden kaçınmak da yaşamsal önem taşımaktadır. Çünkü, hastalık görece olarak yeni tanımlanmıştır ve ideal tedavisi hakkında farklı görüşler mevcuttur. Çocuk hastalarda ailenin bilgilendirilmesinin önemi de hatırlanmalıdır.

\section{KAYNAKLAR}

1. Parvizi J, Leunig M, Ganz R. Femoroacetabular impingement. J Am Acad Orthop Surg 2007;15(9):561-70.

2. Parvizi J, Campfield A, Clohisy JC, Rothman RH, Mont MA. Management of arthritis of the hip in the young adult. J Bone Joint Surg Br 2006;88(10):1279-85.

3. Leunig M, Fraitzl CR, Ganz R. Early damage to the acetabular cartilage in slipped capital femoral epiphysis. Therapeutic consequences. Orthopade 2002;31(9):894-9.

4. Notzli HP, Wyss TF, Stoecklin CH, Schmid MR, Treiber K, Hodler J. The contour of the femoral head-neck junctions as a predictor for the risk of anterior impingement. J Bone Joint Surg Br 2002;84(4):556-60.

5. Cross MB, Fabricant PD, Maak TG, Kelly BT. Impingement (acetabular side). Clin Sports Med 2011;30:379-90. Crossref

6. Myers S, Eijer H, Ganz R. Anterior femoroacetabular impingement after Periacetabular osteotomy. Clin Orthop Relat Res 1999;(363):93-9.

7. Wenger DR, Kishan S, Pring ME. Impingement and childhood hip disease. J Pediatr Orthop B 2006;15(4):233-43.

8. Kocher M, Kim Y, Millis M, Mandiga R, Siparsky P, Micheli LJ, Kasser JR. Hip arthroscopy in children and adolescents. J Pediatr Orthop 2005;25(5):680-6.

9. Siebenrock K, Wahab K, Werlen S, Kalhor M, Leunig M, Ganz R. Abnormal extension of the femoral head epiphysis as a cause of cam impingement. Clin Orthop Relat Res 2004;(418):54-60.
10. Philippon MJ, Briggs KK, Johnston TL, Schenker M, Briggs KK. Clinical presentation of femoroacetabular impingement. Knee Surg Sports Traumatol Arthrosc 2007;15(8):1041-7.

11. Tanzer $M$, Noiseux $N$. Osseous abnormalities and early osteoarthritis: the role of hip impingement. Clin Orthop Relat Res 2004;(429):170-7.

12. Philippon MJ, Ejnisman L, Pennock AT, Ho C, Herzog M, Lertwanich P, Briggs KK. Does femoral anteversion play a role in the pathomechanics and subsequent surgical treatment of femoroacetabular impingement? Arthroscopy 2011;27(5 Suppl):e53.

13. Mardones RM, Gonzalez C, Chen Q, Zobitz M, Kaufman KR, Trousdale RT. Surgical treatment of femoroacetabular impingement: evaluation of the effect of the size of the resection. J Bone Joint Surg Am 2005;87(2):273-9.

14. Philippon M, Ejnisman L, Ellis H, Briggs KK. Outcomes 2 to 5 years following hip arthroscopy for femoroacetabular impingement in the patients aged 11 to 16 years. Arthroscopy 2012;28(9):1255-61. Crossref

15. Wenger DR, Oswald T, Mahar A, Goodwin R. Screw head impingement in treated SCFE: need for surgeon attention to both screw tip and screw head position. Presentation: POSNA Annual Meeting; Ottawa, Ontario, Canada, 2005.

16. Boyer DW, Mickelson MR, Ponseti IV. Slipped capital femoral epiphysis. Long-term follow-up study of one hundred and twenty-one patients. J Bone Joint Surg Am 1981;63(1):85-95.

17. Leunig $M$, Casillas MM, Hamlet M, Hersche $O$, Notzli $H$, Slongo T, Ganz R. Slipped capital femoral epiphysis: early mechanical damage to the acetabular cartilage by a prominent femoral metaphysis. Acta Orthop Scand 2000;71(4):370-5.

18. Southwick WO. Osteotomy through the lesser trochanter for slipped capital femoral epiphysis. J Bone Joint Surg Am 1967;49(5):807-35.

19. Imhäuser G. Late results of Imhäuser's osteotomy for slipped capital femoral epiphysis. Z Orthop Ihre Grenzgeb 1977;115(5):716-25.

20. Dunn DM. The treatment of adolescent slipping of the upper femoral epiphysis. J Bone Joint Surg Br 1964;46:621-9.

21. Spencer $S$, Millis M, Kim Y. Early results of treatment of hip impingement syndrome in slipped capital femoral epiphysis and pistol grip deformity of the femoral head-neck junction using the surgical dislocation technique. J Pediatr Orthop 2006;26(3):281-5.

22. Snow SW, Keret D, Scarangella S, Bowen JR. Anterior impingement of the femoral head: a late phenomenon of LeggCalvé-Perthes' disease. J Pediatr Orthop 1993;13(3):286-9.

23. Philippon MJ, Wolff AB, Briggs KK, Zehms CT, Kuppersmith DA. Acetabular rim reduction for the treatment of femoroacetabular impingement correlates with preoperative and postoperative center-edge angle. Arthroscopy 2010;26(6):757-61. Crossref

24. Bankes MJ, Catterall A, Hashemi-Nejad A. Valgus extension osteotomy for 'hinge abduction' in Perthes' disease. Results at maturity and factors influencing the radiological outcome. J Bone Joint Surg Br 2000;82(4):548-54.

25. Coates CJ, Paterson JM, Woods KR, Catterall A, Fixsen JA. Femoral osteotomy in Perthes' disease. Results at maturity. J Bone Joint Surg Br 1990;72(4):581-5. 